\title{
BMJ Open Anaesthesia-related complications and side-effects in TAVI: a retrospective study in Germany
}

\author{
Sophia Goldfuss, ${ }^{1}$ Sigrid Wittmann, ${ }^{1}$ Fabian Würschinger, ${ }^{1}$ Diane Bitzinger, ${ }^{1}$ \\ Timo Seyfried, ${ }^{1}$ Andreas Holzamer, ${ }^{2}$ Marcus Fischer, ${ }^{3}$ Daniele Camboni, ${ }^{2}$ \\ Barbara Sinner, ${ }^{1}$ York Alexander Zausig ${ }^{1,4}$
}

To cite: Goldfuss S, Wittmann $S$, Würschinger $F$, et al. Anaesthesia-related complications and sideeffects in TAVI: a retrospective study in Germany. BMJ Open 2019;9:e025825. doi:10.1136/ bmjopen-2018-025825

- Prepublication history for this paper is available online. To view these files, please visit the journal online (http://dx.doi. org/10.1136/bmjopen-2018025825).

Received 8 August 2018 Revised 19 February 2019 Accepted 28 February 2019

Check for updates

(c) Author(s) (or their employer(s)) 2019. Re-use permitted under CC BY-NC. No commercial re-use. See rights and permissions. Published by BMJ.

${ }^{1}$ Department of Anaesthesiology, Universitatsklinikum Regensburg, Regensburg, Germany

${ }^{2}$ Department of Cardiothoracic Surgery, Universitatsklinikum Regensburg, Regensburg, Germany

${ }^{3}$ Department of Cardiology, Universitatsklinikum Regensburg, Regensburg, Germany

${ }^{4}$ Department of Anaesthesiology and Operative Intensive

Care Medicine, Klinikum Aschaffenburg, Aschaffenburg, Germany

Correspondence to

Professor York Alexander Zausig; york.zausig@ukr.de

\section{ABSTRACT}

Objectives This study was performed to analyse anaesthesia-related complications and side effects in patients undergoing transcatheter aortic valve implantation (TAVI) under general anaesthesia.

Design Retrospective study.

Setting The study was performed as a single-centre study in a hospital of tertiary care in Germany.

Participants All 853 patients, who underwent TAVI at the Universitätsklinikum Regensburg between January 2009 and July 2015, were included. 52.5\% were female patients.

Primary and secondary outcome measures We gathered information, such as recent illness, vital parameters and medication administered during the intervention and postoperatively for 12 hours. We analysed all anaesthesia-related complications and anaesthesiarelated side effects that occurred during the intervention and entire hospital stay.

Results We analysed all 853 TAVI procedures. The mean patient age was $79 \pm 6$ years. In $99.5 \%$ of cases, we used volatile-based anaesthesia. $2.8 \%(n=24$; transfemoral (TF): $n=19$ [3.8\%]; transapical (TA): $n=5[1.4 \%]$ ) of all cases suffered from anaesthesia-related complications. 819 (TF: $n=447 ; T A: n=372$ ) anaesthesia-related side effects occurred in 586 (68.7\%, TF: $n=325$ [64.2\%], TA: $n=261$ $[75.2 \%]$ ) patients. Neither the complications nor the side effects had any serious consequences. Intraoperative hypothermia in 44\% of cases (TF: $n=202$ [39.9\%]; TA: $\mathrm{n}=173[49.9 \%])$ and postoperative nausea and vomiting in $27 \%$ ( $n=232 ;$ TF: $n=131$ [25.9\%], TA: $n=101$ [29.1\%]) of cases were the most common anaesthesia-related side effects.

Conclusion In this study, serious anaesthesia-related complications were rarely seen, and non-critical anaesthesia-related side effects could have been avoided through consistent prophylaxis and management. Therefore, despite their high anaesthetic risk, general anaesthesia is justifiable in patients who underwent TAVI.

\section{INTRODUCTION}

As life expectancy is increasing worldwide, a growing number of elderly multimorbid patients will require surgery and anaesthesia in the future. In the 16 million interventions that took place in Germany in 2013, $42 \%$ of
Strengths and limitations of this study

- Our study is retrospective and not prospective randomised.

- Due to the retrospective study design, inconsistent documentation cannot be excluded.

- We can provide reliable data because of the large study size.

- Multivariable analysis was used to minimise confounding bias.

- This manuscript focusses on anaesthesia-related complications and side effects in patients who underwent transcatheter aortic valve implantation.

the patients were older than 65 years. ${ }^{1}$ The number of pre-existing diseases, the American Society of Anesthesiologists (ASA) status and therefore the perioperative risk increase with older age. ${ }^{2}{ }^{3}$ Many interventions are increasingly performed on high-risk patients to meet the needs of an older and multimorbid patient population. Therefore, minimally invasive techniques are increasing. One of these minimally invasive procedures is transcatheter aortic valve implantation (TAVI) in patients with aortic valve stenosis. TAVI may be performed in patients with high and moderate surgical risks by dispensing with invasive measures, such as sternotomy and cardioplegia. ${ }^{4}$ Currently, TAVI is performed under local anaesthesia (LA) or general anaesthesia (GA). GA might offer comfortable conditions for intervention, for example, the use of transoesophageal echocardiography (TEE), for a safe and optimal valve implantation. ${ }^{56}$

Anaesthesia-related complications and mortality have been significantly reduced in the last years. ${ }^{7}$ Nevertheless, anaesthesia-related side effects, such as postoperative nausea and vomiting (PONV) or delirium, should not be underestimated. First, patients fear anaesthetic side effects. ${ }^{89}$ Second, these 
side effects are also organisationally and economically challenging because they may lead to prolonged hospital stays and are associated with high healthcare costs. ${ }^{10-12}$ This study examines anaesthesia-related complications and side effects in patients undergoing TAVI.

\section{METHODS}

In this study, after obtaining the consent of the University of Regensburg's Ethics Commission, all data from each TAVI procedure performed at the University Hospital Regensburg between January 2009 and July 2015 were retrospectively obtained and analysed for anaesthesia-related complications and anaesthesia-related side effects. Some data (eg, procedural time, intervention related complications, acute kidney injury) have already been presented elsewhere. $^{13}$

\section{Data}

Data were acquired from anaesthetic charts (Medling V.1.3, Hamburg, Germany), the patient document system used in the intensive care unit (ICU) and intermediate care unit (IMC) (Metavision, iMDsoft, Tel Aviv, Israel) and medical reports from the electronic hospital information system (SAP, Walldorf, Germany) from the preoperative, intraoperative, and postoperative periods until the patients were discharged from the hospital.

Demographic data, such as age, sex, body mass index (BMI), ASA, New York Heart Association Functional Classification, European System for Cardiac Operative Risk Evaluation (EuroSCORE), anaesthesia-related parameters, side effects, complications and risk scores, clinical characteristics and recent illness, were obtained. ${ }^{1415}$ Vital sign measurements (ie, heart rate, blood pressure and $\mathrm{SpO}_{2}$ ) at defined times, as well as drugs administered throughout the TAVI procedure and in the ICU (first 12 hours), were acquired. ${ }^{13}$

We differentiated between side effects and complications. Anaesthesia-related side effects included: hypoxaemia $\left(\mathrm{SpO}_{2}<90 \%\right)$, hypothermia (body temperature $<36^{\circ} \mathrm{C}$ ), hypotension (intraoperatively, Mean Arterial Pressure (MAP) $<50 \mathrm{~mm} \mathrm{Hg}$; postoperatively, MAP $<60 \mathrm{~mm} \mathrm{Hg}$ ), delirium and PONV (all patients who suffered from PONV or delirium and were treated and/ or had a note in their medical reports)..$^{10-18}$ Anaesthesia-related complications included cardiac arrest not directly associated with the intervention itself, difficult airway management and airway damage, laryngospasm, allergic reaction and vascular damage.

\section{Procedure}

All procedures were performed according to the German guidelines for TAVI procedures. ${ }^{19}$ Prior to GA, the patients received oral premedication (ie, dipotassium clorazepate, melperone, zopiclone or midazolam), depending on each patient's risk and the anaesthesiologist's preferences.
The intervention was performed in general as follows: after being placed on a warming system, each patient received two intravenous cannulas, an arterial line in the radial artery and a central venous catheter in the internal jugular vein or the subclavian vein. Bladder catheters, with temperature measurement, were used in each patient. The patients received right ventricular pacemakers for rapid ventricular pacing during balloon aortic valvuloplasty and valve expansion. Preoxygenation was performed with pure oxygen using a facemask. In general, the anaesthetic induction regimen consisted of bolus doses of etomidate, rocuronium bromide and a continuous infusion of remifentanil. Anaesthesia was maintained with sevoflurane or desflurane. Piritramide and metamizole were used as additional pain medication. PONV prophylaxis was used intraoperatively, depending on the patient's risk. Cardiovascular drugs (eg, norepinephrine and dobutamine) were administered as needed. The responsible cardiac anaesthesiologist decided about the medication type and dose. The patients received endotracheal intubation. Respiratory gases were sampled at the filter and continuously displayed by the ventilator. Antibiotic prophylaxis with cefuroxime was applied immediately before the procedure. The intraoperative monitoring included 5-lead ECG, pulse oximetry, invasive blood pressure, central venous pressure, heart rate, respiration parameters, bladder temperature and serial arterial blood gas analysis. Intraoperative TEE was performed, if possible. Heparin $(0.5-1 \mathrm{IU} / \mathrm{kg})$ was administered intraoperatively. The anticoagulant effect was monitored with an activated coagulation time value $>250 \mathrm{~s}$. At the end of the procedure, heparin was antagonised with protamine on a 1:1 basis. The goal was to perform tracheal extubation in the operating room. In cases of intervention-related complications or hypothermia $<36^{\circ} \mathrm{C}$, the time of extubation was decided on a case-by-case basis. After the intervention, the patients were immediately transferred to one of our three ICUs for monitoring. Depending on their physical condition, they were taken to the general ward or an IMC afterwards. ${ }^{13}$

\section{Patient and public involvement}

Patients were not involved in the study.

\section{Statistics}

For the data collection, we used Excel (Excel 2013, Microsoft Corporation, Redmond, Washington, USA). We analysed the data with SPSS (IBM SPSS Statistics V.24.0 for Windows, IBM Corporation). Frequency distributions and percentage rates were used for the categorical variables. Data are displayed as the mean \pm SD deviation or median with range. We used the $\chi^{2}$ test (based on Pearson's $\chi^{2}$ test), the two-sided t-test and univariate and multivariate logistic regression analyses to compare the transapical (TA) group and the transfemoral (TF) group. $\mathrm{P}<0.05$ was regarded as statistically significant. 
RESULTS

\section{Patients}

A total of $853 \mathrm{TF}$ and TA TAVIs were performed during the study period. All cases could be analysed retrospectively. TF access was selected in 506 patients (59.3\%), while TA-TAVI was performed in 347 patients (40.7\%). In most of the cases, Medtronic Edwards SAPIEN (Edwards Lifesciences Corporation, Irvine, California, USA) $(n=420[49 \%])$ and Symetis Valves (Boston Scientific Corporation, Marlborough, Massachusetts, USA) $(\mathrm{n}=219$ [26\%]) were implanted. CoreValve (CoreValve Revalving System, Medtronic, Minneapolis, USA) was used in $16 \%$ of the cases $(n=134)$. In the rest of the cases $(n=80)$, the valve type could not be gathered from our sources. ${ }^{13}$

The mean patient age was $79 \pm 6$ years, and the mean BMI was $27 \pm 5 \mathrm{~kg} / \mathrm{m}^{2}$. In total, $98.8 \%$ of the TF group and $98.2 \%$ of TA patients had an ASA status of 3 or higher. Demographic data, as well as basic preoperative data, previous illnesses and an overview of the current airway classifications of the patients are summarised in table 1. In three TF patients $(0.4 \%)$, a 'difficult airway' was documented in the premedication protocol.

All procedures were performed under GA. A total of $849(99.5 \%)$ procedures took place under volatile-based anaesthesia. Total intravenous anaesthesia was used in four TA procedures.

\section{Anaesthesia-related complications}

Twenty-six anaesthesia-related complications occurred in 24 patients of the 853 patients (2.8\%). Twenty-one complications occurred in TF $(n=19 ;[3.8 \%])$ and five in TA $(n=5 ;[1.4 \%])$. Among these complications were six $(0.7 \%)$ difficult intubations, one $(0.1 \%)$ aspiration, eight $(0.9 \%)$ airway damages, three $(0.4 \%)$ tooth damages, two $(0.2 \%)$ laryngospasms, three $(0.4 \%)$ allergic reactions, two $(0.2 \%)$ vascular damages and one $(0.1 \%)$ cardiopulmonary resuscitation (CPR) before the start of the intervention (table 2).

This was a TF patient with a EuroSCORE of 19, a pre-existing pneumonia and recurrent syncope. Following a risk assessment, it was nevertheless decided to continue the intervention. Pulseless electrical activity was noted during induction. Successful CPR of the patient was performed. The patient was hypothermic $\left(35.1^{\circ} \mathrm{C}\right)$ after successful TAVI, so the trachea of the patient could not be extubated. He was transferred to the ICU and successfully extubated after 68 hours, moved to a normal ward after 8 days and was discharged after 17 days. In our view, there were several reasons attributable for the cardiac arrest.

\section{Anaesthesia-related side effects}

Furthermore, 819 anaesthesia-related side effects occurred in 586 of all 853 patients (68.7\%; TF: $n=325$ [64.2\%], TA: $n=261[75.2 \%])$. These side effects are listed in table 2.

\section{PONV}

A total of 232 patients suffered from PONV requiring therapy. Female gender $(\mathrm{p}<0.001)$, a history of PONV $(\mathrm{P}=0.036)$ and postoperatively administered opioids $(\mathrm{p}=0.015)$ were significant risk factors. The PONV rate $(27.7 \%)$ was not significantly elevated $(\mathrm{p}=0.112)$ in non-smokers $(\mathrm{n}=819)$ compared with smokers $(\mathrm{n}=32$; [15.2\%]). Age, BMI and the duration of the intervention also had no statistically significant effect on the PONV rate. The average Apfel risk score for PONV was $2.2 \pm 0.8$ for all patients. The PONV risk increased by $78.3 \%$ for each score point $(\mathrm{p}<0.001)$. An overview of the patients' Apfel score is shown in table 1.

Overall, $17.5 \% \quad(n=149)$ of the patients received PONV prophylaxis intraoperatively. A maximum of two agents were administered per patient for prophylaxis. Figure 1 shows the number of agents administered, depending on the Apfel risk score for PONV.

The incidence of PONV in patients with at least two PONV risk factors was reduced from $31.5 \%$ to $25.8 \%$ $(\mathrm{p}=0.24)$ through prophylaxis. Figure 2 shows the incidence of PONV depending on the Apfel score with and without intraoperative PONV prophylaxis.

\section{Delirium}

Of the 74 patients with delirium, $30(40.5 \%)$ belonged to the TF group, while $44(59.5 \%)$ belonged to the TA group $(\mathrm{p}=0.001)$. The multivariate analysis showed that male gender $(p=0.038)$, transapical access $(p=0.001)$ and pre-existing dementia $(\mathrm{p}=0.047)$ influenced the delirium rate significantly and independently. Neither the lack of extubation in the surgical room $(10.2 \%$ vs $8.5 \%, \mathrm{p}=0.573)$ nor intervention-related intraoperative complications influenced the incidence of delirium $(\mathrm{p}=0.413)$. Multivariate regression analysis showed that delirium had a significant influence on length of stay (LOS) at ICU $(\mathrm{p}=0.012)$, IMC $(p<0.001)$ and in hospital $(p=0.033$; figure 3$)$.

\section{Hypothermia}

The body temperature at extubation was available for 781 patients. Three hundred and seventy-five of them (44.0\%) were hypothermic by $0.8 \pm 1.1$ degrees on average. A total of 264 patients had a body temperature $>35^{\circ} \mathrm{C}$, and 47 patients had a body temperature $<35^{\circ} \mathrm{C}$.

The risk of hypothermia in the surgical room decreased with increasing weight $\left(4.3 \%\right.$ per $\left.\mathrm{kg} / \mathrm{m}^{2} ; \mathrm{p}=0.05\right)$. TA access $(p=0.025)$, BMI category $(p=0.016)$ and age older than 80 years $(p=0.031)$ were independent and significant risk factors for the occurrence of hypothermia in the multivariate analysis. Intervention-related complications were no risk factors.

Intervention in the hypothermic group lasted $1: 29 \pm 0: 44$ hours and was 5 min longer on average. This difference was not statistically significant $(\mathrm{p}=0.151)$. The induction in both groups was of the same duration, lasting an average of 0:38 $\pm 0: 11$ hours.

Neither the postoperative complication rate $(\mathrm{p}=0.956)$ nor the mortality rate $(\mathrm{p}=0.314)$ was significantly 
Table 1 Patient demographics and anaesthesia-related variables

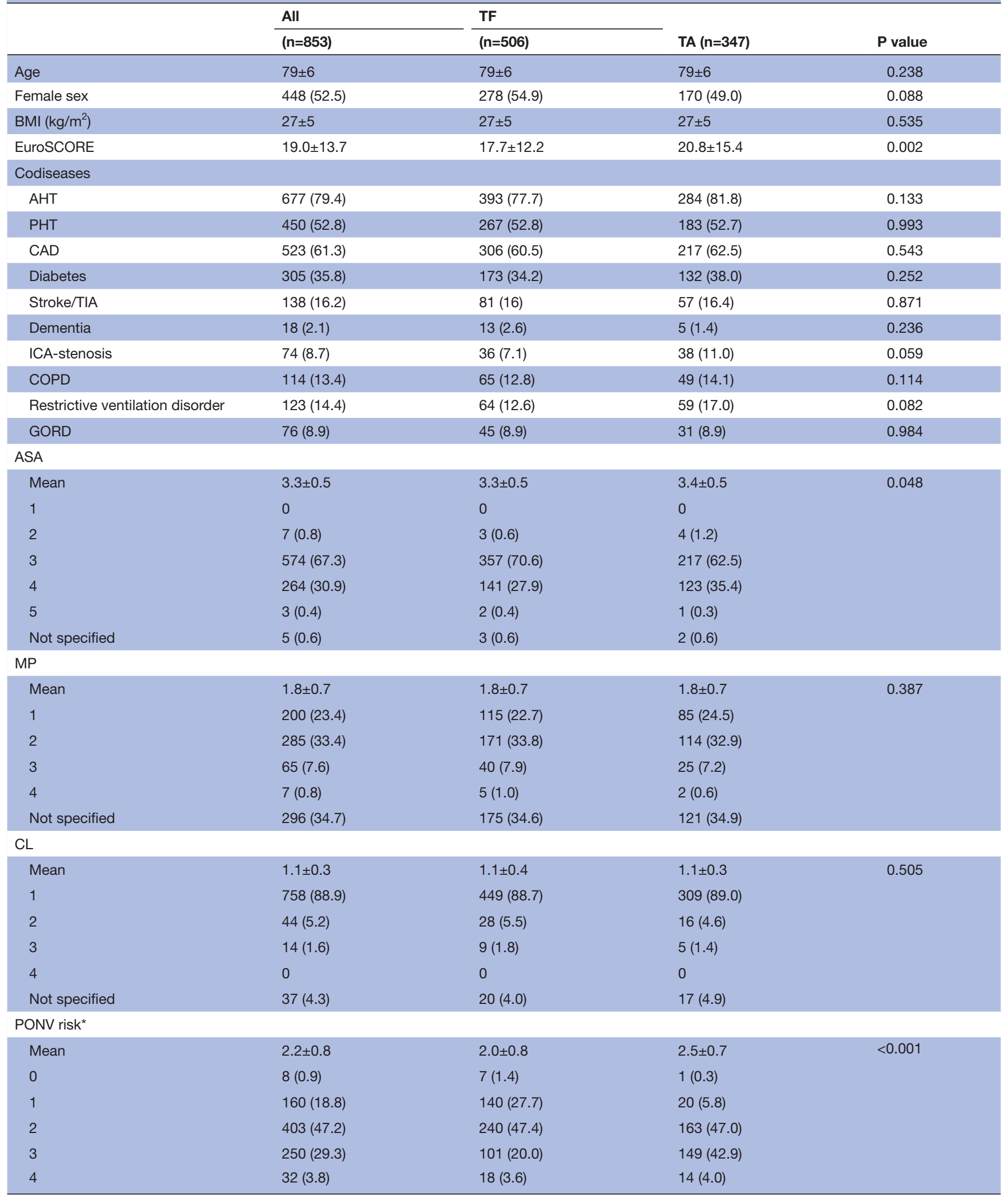

*Score from Apfel; AHT, arterial hypertension; all data are presented as $\mathrm{n}$ (number) and (\%) or as the mean $\pm \mathrm{SD}$.

ASA, American Society of Anaesthesiologists Classification; BMI, body mass index; CAD, coronary artery disease; CL, Cormack-Lehane Score; COPD, chronic obstructive pulmonary disease; EuroSCORE, European System for Cardiac Operative Risk Evaluation; GORD, gastro-oesophageal reflux disease; ICA-stenosis, relevant stenosis of the internal carotid artery; MP, Mallampati Score; PHT, pulmonary hypertension, PONV, postoperative nausea and vomiting; TA, transapical; TF, transfemoral; TIA, transient ischaemic attack. 
Table 2 Anaesthesia-related complications and side effects

\begin{tabular}{|c|c|c|c|c|}
\hline & All: $n=853$ & TF: $n=506$ & TA: $n=347$ & $P$ value \\
\hline Complications & $26^{*}$ & $21^{*}$ & $5^{\star}$ & \\
\hline Preoperative CPR & $1(0.1)$ & $1(0.2)$ & $0(0)$ & 0.407 \\
\hline $\begin{array}{l}\text { Tracheal tube } \\
\text { misplacement }\end{array}$ & $0(0)$ & $0(0)$ & $0(0)$ & \\
\hline Tooth damage & $3(0.4)$ & $1(0.2)$ & $2(0.6)$ & 0.403 \\
\hline Laryngospasm & $2(0.2)$ & $2(0.4)$ & $0(0)$ & 0.158 \\
\hline Allergic reaction & $3(0.4)$ & $3(0.6)$ & $0(0)$ & 0.083 \\
\hline Vascular damage & $2(0.2)$ & $2(0.4)$ & $0(0)$ & 0.158 \\
\hline Intraoperative & $436^{\star}$ & $238^{*}$ & $198^{\star}$ & \\
\hline Hypothermia & $375(44.0)$ & 202 (39.9) & 173 (49.9) & 0.004 \\
\hline Hypotension & $61(7.1)$ & $36(7.1)$ & $25(7.2)$ & 0.96 \\
\hline Postoperative & $308^{*}$ & $161^{*}$ & $147^{*}$ & \\
\hline PONV & $232(27.2)$ & $131(25.9)$ & $101(29.1)$ & 0.304 \\
\hline Delirium & $74(8.7)$ & $30(5.9)$ & $44(12.7)$ & 0.001 \\
\hline Narcotic hangover & $2(0.2)$ & $0(0)$ & $2(0.6)$ & 0.158 \\
\hline
\end{tabular}

All data are presented as $\mathrm{n}$ (number) and (\%) (=patients with complications or side effects related to the total number of patients in this subgroup).

${ }^{\star}$ Total number of complications and side effects; some patients suffered from more than one complication or side effect.

†Before the start of anaesthesia.

CPR, cardiopulmonary resuscitation; PONV, postoperative nausea and vomiting; TF, transfemoral; TA, transapical.

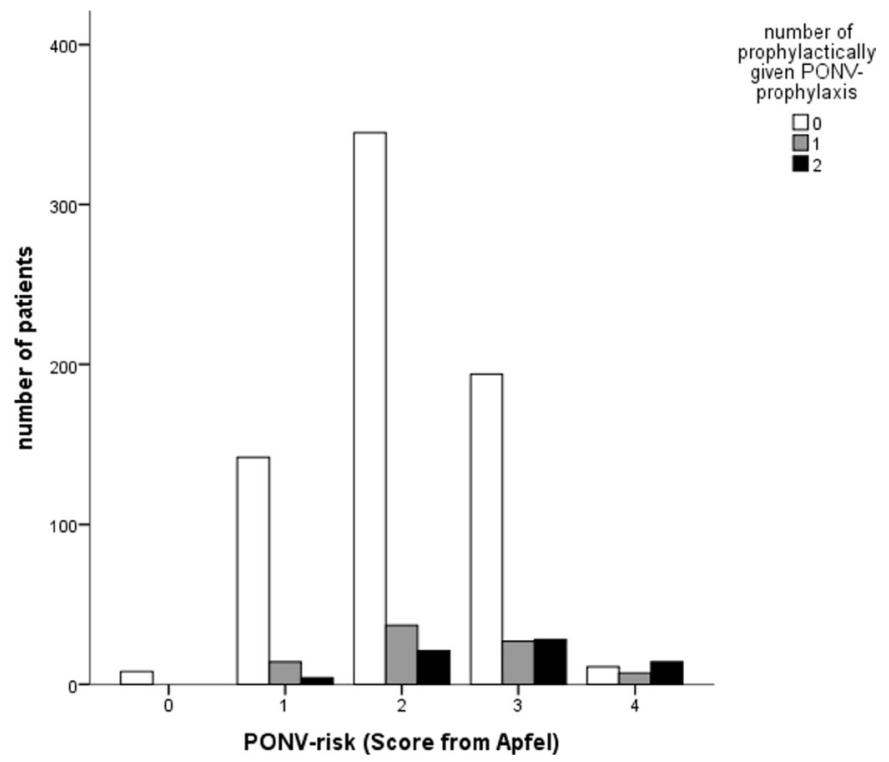

Figure 1 Number of prophylactically administered postoperative nausea and vomiting (PONV) medications, depending on the patients' PONV risk. All data are presented as $n$ (number).

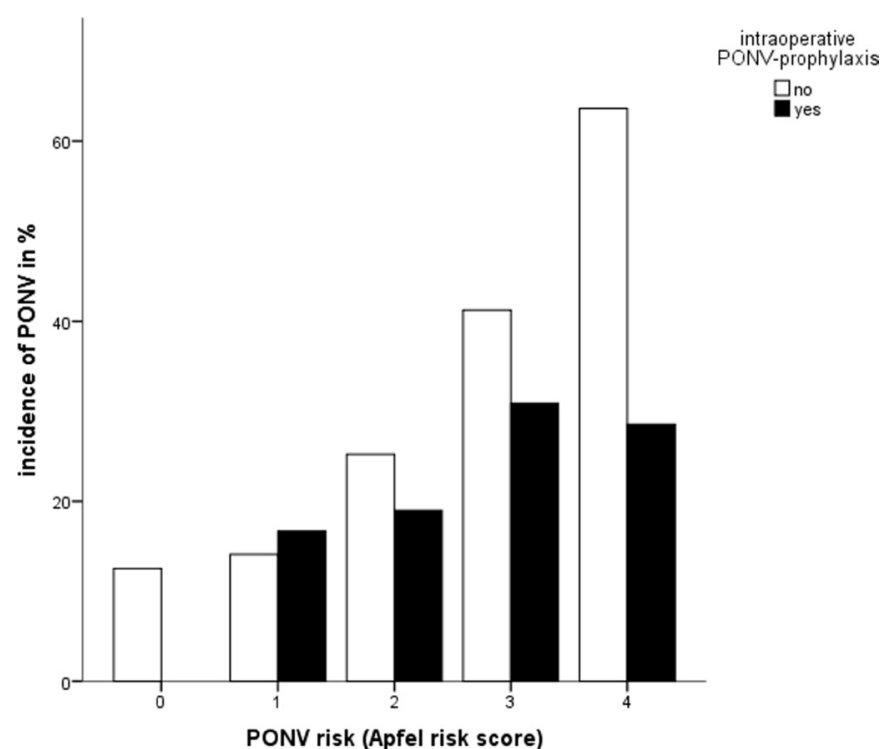

Figure 2 Incidence of postoperative nausea and vomiting (PONV), depending on the patient's PONV risk: intraoperative prophylaxis versus no prophylaxis. 1 : $p=0.746 ; 2$ : $p=0.34 ; 3$ : $\mathrm{p}=0.213 ; 4: \mathrm{p}=0.055$. All data are presented in per cent. 


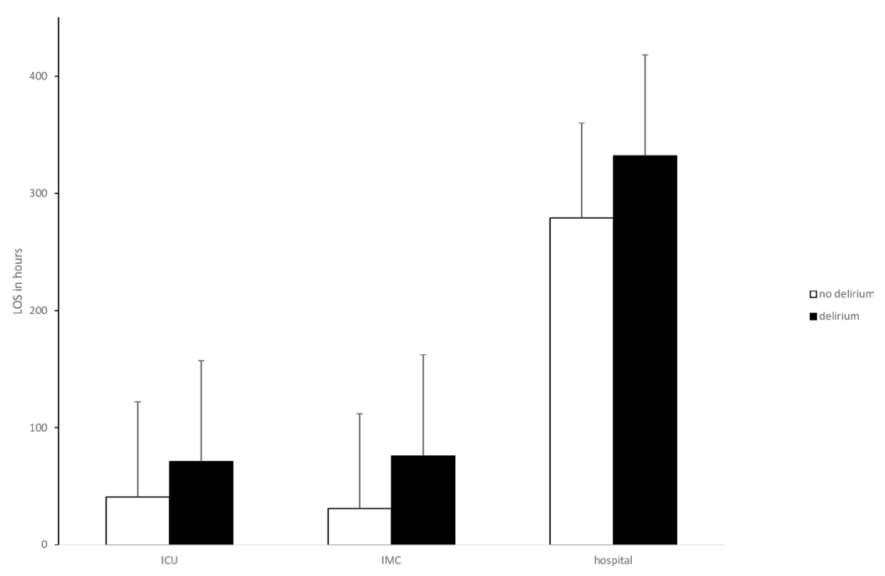

Figure 3 Length of stay (LOS) in the intensive care unit (ICU), intermediate care unit (IMC) and hospital for patients with delirium versus patients without delirium. ICU: $p=0.054$; IMC: $p=0.002$; hospital: $p=0.035$. All data are presented as mean \pm SD.

increased in the patients with hypothermia compared with the patients with normothermia.

\section{Delayed postoperative extubation}

A total of 100 patients were not extubated in the operating room ([11.7\%]; TF: $\mathrm{n}=51$ [10.1\%], TA: $\mathrm{n}=49$ [14.1\%], figure 3). Fifty-nine of the patients were not extubated due to intervention-related complications (eg, bleeding, intraoperative stroke and myocardial infarction, intraoperative CPR). Hypothermia $\left(\leq 35^{\circ} \mathrm{C}, \mathrm{n}=11 ;>35^{\circ} \mathrm{C}, \mathrm{n}=11\right)$ was the second most common cause $(\mathrm{n}=22)$ (figure 4$)$. In addition, 10 patients were not extubated due to pre-existing conditions (chronic obstructive pulmonary disease [COPD] and pre-existing pneumonia) and nine patients were not extubated due to interventional causes (prophylactic extracorporeal membrane oxygenation (ECMO) protection, concomitant operative coronary artery bypass grafting) (figure 4).

A total of $92 \%$ (TF: $n=45$ [88.2\%], TA: $n=47$ [95.9\%]) of the 100 non-extubated patients were extubated during their hospital stay. Sixty-five $(70.7 \%))$ of these 92 patients were extubated postoperatively within the first 24 hours. All 22 patients, who were not extubated only because of hypothermia, could be extubated within 27 hours.

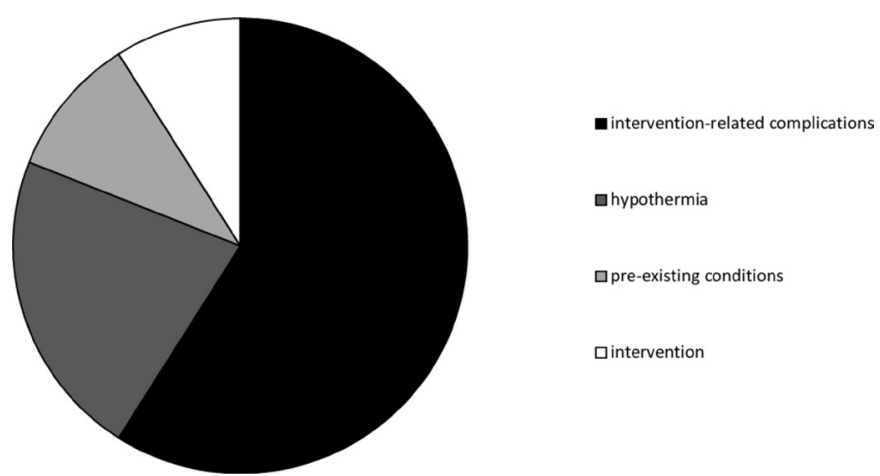

Figure 4 Causes for non-extubation in the surgical room. All data are presented in per cent.
The pneumonia rate in the non-extubated patients was significantly higher $(15.0 \%$ vs $6.2 \%, p=0.002)$. Ten of the 15 patients $(66.7 \%)$, who developed pneumonia postoperatively, were not extubated due to complications. Two $(13.3 \%)$ of the patients who developed pneumonia were not extubated due to hypothermia.

Sixteen $(17.4 \%)$ of the 92 patients, who were extubated with delay, died during their hospital stay. In all, 24 $(24.0 \%)$ of those patients who were not extubated in the operating theatre died. None of these deceased patients was not extubated due to hypothermia.

\section{Hypoxaemia}

Pulsoxymetric oxygen saturation was observed in 732 patients before the start of anaesthesia, and 75 of these patients $(10.5 \%)$ were hypoxaemic. Fifty-three of these patients $(70.7 \%)$ suffered from mild hypoxaemia $\left(\mathrm{SpO}_{2} 85-90\right)$, while 22 patients $(29.3 \%$, TF: $\mathrm{n}=6$, TA: $\mathrm{n}=16)$ had severe hypoxaemia $\left(\mathrm{SpO}_{2} \leq 85\right)$. Of the 75 patients with hypoxaemia, 46 patients $(61.3 \%, \mathrm{p}=0.065)$ received midazolam as premedication. Midazolam as premedication was given in 375 cases.

BMI (28.6 \pm 5.6 vs $26.5 \pm 4.7 ; \mathrm{p}=0.001)$, the logistic EuroSCORE $(16.3 \pm 1.9$ vs $13.2 \pm 0.5 ; \mathrm{p}=0024)$, pre-existing pulmonary restriction $(\mathrm{p}=0.0002)$ and pulmonary hypertension $(\mathrm{p}=0.037)$ were independent significant risk factors for hypoxaemia in the multivariate regression analysis. In addition, the amount of midazolam used as premedication correlated with the hypoxaemia rate. The hypoxaemia rate increases by $12.7 \%$ for each milligram of administered midazolam $(\mathrm{p}=0.028)$. However, this did not prove to be an independent, significant risk factor for hypoxaemia $(\mathrm{p}=0.076)$.

Pre-existing COPD or an obstruction detected on spirometry also demonstrated no significant effect on the hypoxaemia rate $(\mathrm{p}=0.534, \mathrm{p}=0.389)$.

A higher mortality rate $(12.0 \%$ vs $5.5 \%)$ was noted among the patients who were hypoxaemic during the induction phase. But in multivariate regression analysis, hypoxaemia did not have any significant effect on the mortality rate $(\mathrm{p}=0.108)$, nor the duration of stay in the ICU $(\mathrm{p}=0.537)$ nor the postoperative complication rate $(\mathrm{p}=0.209)$.

\section{DISCUSSION}

Overall, serious anaesthesia-related complications were rare. The complications mainly included mild respiratory lesions and difficult intubation. Side effects occurred in approximately $70 \%$ of the patients. However, most of these effects did not have any serious consequences and potentially could have been avoided in most patients. Furthermore, many of these side effects might be multifactorial. The most common side effects were intraoperative hypothermia in 375 cases and PONV in 232 cases. TA access and low BMI proved to be risk factors for hypothermia. The primary risk factors for the occurrence of PONV were female 
gender, postoperatively administered opioids and a history of PONV.

Schiff $e t$ al have reported that the rate of severe anaesthesia-related complications is 26.2 per million anaesthesia cases. ${ }^{7}$ However, Schwilk et al have reported a complication rate of $35 \%$ among 23000 anaesthetised patients. ${ }^{20}$ Overall, the rate of anaesthesia-related complications in our study was almost $3 \%$. Comparing these heterogeneous complication rates proved to be difficult because the methodologies and assessments of the complications differed among the studies. In addition, these studies involved different interventions and different patient populations. The perioperative risk increases significantly with increasing ASA status and age. ${ }^{23}$ In the present study, the patients had an average ASA status of $3.3 \pm 0.5$, whereas in the study of Schwilk et al, more than half of the patients had an ASA status of 1 or 2; Schiff et al exclusively studied anaesthesia in patients with an ASA status of 1 or $2 .{ }^{720}$ In addition, Schiff et al excluded milder anaesthesia-related complications, such as tooth damage, and so on, from their investigations. ${ }^{7}$ In contrast, the present study provides an overview of all described complications.

The incidence of delirium is reported between $8 \%$ and $54 \%$ in elderly patients and $21 \%$ following invasive cardiac surgery. ${ }^{21} 22$ The incidence of delirium after TAVI is reported as $29 \%$ in the literature. ${ }^{23}$ The incidence of delirium in our study was $8.7 \%$. The reported incidences of delirium vary greatly, depending on the study design. Retrospective analyses of patient data are associated with the lowest incidences of delirium. ${ }^{11}$ The far more frequently observed type of hypoactive delirium is easily overlooked in clinical practice and is not documented. ${ }^{1124}$ Therefore, approximately two-thirds of all delirium cases are not recognised. ${ }^{24}$ Maniar et al have also documented that hypoactive delirium is the most frequent type of delirium in patients who underwent TAVI. Delirium occurs significantly more frequently following TA then TF procedures. ${ }^{23}$ This difference was also confirmed in the present study. This can probably be explained by the overall worse pre-existing conditions of TA patients. They had a significantly higher EuroSCORE and ASA status in our study. Furthermore, the invasiveness of the procedure itself and postoperative pain might be risk factors. ${ }^{23}$ Maniar et al showed that the incidence of postoperative delirium in surgical aortic valve replacement or TAVI is almost comparable ( $33 \%$ vs $29 \%$; $=0.4) .{ }^{23}$

Overall, more than 95 risk factors are listed in the literature, with marked heterogeneity. ${ }^{21}$ The following primary risk factors for the occurrence of delirium after cardiac surgery have been described: cognitive impairment, such as pre-existing dementia, hypoalbuminaemia, depression and post-TIA or stroke status. ${ }^{11}{ }^{22}$ Pre-existing dementia was also found to be a statistically significant risk factor for the occurrence of delirium in the present study. Furthermore, delirium leads to prolonged ICU and hospital stays and is therefore associated with high costs. ${ }^{112123}$ These findings were also observed in our study.
The postoperative mortality and morbidity rates are also higher in patients with delirium, according to the literature. $^{112324}$ The incidence of pneumonia is particularly high in patients with delirium. ${ }^{24}$ Patients with delirium also demonstrated a significantly higher incidence of pneumonia in the present study. This increase in the incidence of pneumonia is likely due to the longer hospital stay, as delirium was not a significant independent risk factor in the multivariate analysis. Although the mortality rate and number of complications were increased in the present study, these differences were not statistically significant.

Depending on the risk constellation, PONV occurs in up to $60 \%$ of cases. ${ }^{25}$ A PONV incidence of $35 \%$ has been described following TAVI. ${ }^{26}$ A PONV incidence of $28 \%$ was observed in the present study. Of the generally known PONV risk factors, female gender and a history of PONV were identified as significant risk factors in the present study. ${ }^{15}$ The PONV rate was also higher in non-smokers; however, this finding was not statistically significant, primarily due to the unequal distribution or documentation of smokers $(n=33)$ and non-smokers $(n=820)$ in the present study.

Furthermore, anaesthesia-related PONV risk factors have been described, particularly the duration of anaesthesia and the intraoperative and postoperative administration of opioids, in addition to the use of inhalational anaesthetic agents and nitrous oxide. ${ }^{12}$ The postoperative administration of opioids also resulted in a significant increase in the PONV rate in our study, while no relationship was observed between the duration of anaesthesia and the PONV rate. PONV prophylaxis is rarely administered, although the principal risk factors for its occurrence are known, and PONV itself is associated with several complications. ${ }^{25}{ }^{27}$ Frenzel et al have described a 36\% compliance for two existing PONV risk factors and $22 \%$ for three existing risk factors during the implementation of appropriate prophylaxis. ${ }^{27}$ PONV prophylaxis was also rarely administered in this study. Only $19 \%$ of patients with an Apfel score $\geq 2$ received appropriate PONV prophylaxis, which may be due to our patient population. On one hand, the PONV risk decreases with increasing age. ${ }^{25}$ Therefore, this rate was possibly underestimated. On the other hand, prophylactically administered $5-\mathrm{HT}_{3}$ antagonists and droperidol significantly reduce the incidence of PONV but also lead to prolonged QT intervals, increasing the risk of torsade-de-pointes tachycardia. ${ }^{12}{ }^{28}$ Patients with cardiac disease, as in the present study, are exposed to this risk, which may be the cause of reduced compliance, although no alternatives were administered. ${ }^{28}$

In the present study, $8.7 \%$ of patients suffered from hypoxaemia before induction, which was mild in $6.2 \%$ of patients and severe in $2.6 \%$. Preoperative premedication is always associated with the occurrence of hypoxaemia. ${ }^{29}$ Royse et al have reported that the incidence of hypoxaemia was $30 \%$ after premedication. ${ }^{29}$ The fact that our incidence is significantly lower could be because Royse et al used a benzodiazepine-opiate combination, which also enhances respiratory depression. ${ }^{30}$ However, 
midazolam alone, used as standard medication because of its low propensity for side effects, also causes respiratory depression. $^{30}{ }^{31}$ Respiratory minute volume drops drastically after midazolam, particularly in patients older than 65 years of age. ${ }^{31}$ In our study, the hypoxaemia rate increased with the amount of midazolam administered as premedication. Therefore, we stopped giving midazolam to patients who underwent TAVI at our hospital. Royse et al have shown that additional oxygen administration after premedication can significantly reduce the incidence of hypoxaemia. They recommend monitoring and oxygen administration immediately after premedication in patients at risk of hypoxaemia. ${ }^{29}$ However, this approach is complex and expensive. In addition, benzodiazepines have a delirogenic potential, which is why premedication in patients undergoing TAVI should be completely eliminated in the future. ${ }^{32}$

There are recent studies comparing LA and GA for TAVI. They show that both ways are comparable in procedure-related outcomes. ${ }^{63-35} \mathrm{LA}$ in TAVI has the advantages of a shorter induction time, more stable haemodynamic conditions, a faster postoperative mobilisation and a shorter LOS. ${ }^{3435}$ GA provides a better patient comfort with more stable surgical conditions. In addition, periprocedural complications can be better controlled. Furthermore, continuous TEE monitoring is possible under GA and thus patients have a reduced incidence of aortic regurgitation. ${ }^{634} 35$ Anaesthesia-related complications and side effects have not been considered in these studies. Our study shows that anaesthesia-related complications are relatively rare, and side effects can be avoided by adequate prophylaxis.

\section{Limitations}

The percentage of TF patients in the collective permanently rose up to $74.4 \%$ during the study period. Furthermore, better operative techniques could reduce complication rates and improve patient outcome. Additionally, other reasons (eg, emergency TAVI, diagnostic related groups (DRG) system, different standard operating procedures on the ICU) might have influenced ICU, IMC and hospital stay. ${ }^{13}$ Complications and side effects seen in this study might not be totally attributable to anaesthesia. For example, delirium arises from different predisposing and precipitating factors. ${ }^{22}$ Therefore, a prospective study might be more sensitive to divide complications and side effects to the main cause.

\section{CONCLUSION}

This study demonstrated a low rate of anaesthesia-related complications. Anaesthesia-related side effects could have been avoided in most of the cases through good prophylaxis. In our opinion, patients who underwent TAVI can decently be managed under GA, and this might offer advantages in the management (eg, use of TEE). However, they need a comprehensive regime throughout their hospitalisation stay. Therefore, due to the results of this study, the organisation of patients who underwent TAVI has been changed in Regensburg: for example, premedication with benzodiazepine is no longer in use and prewarming has been recognised as an important standard by all colleagues.

Contributors YAZ and SW originated the idea and performed preliminary data evaluation. SG and FW continued to perform data evaluation. YAZ, DB, TS and SW analysed the data. YAZ and SG were responsible for writing the paper. AH, MF, BS and DC supported the editing of the manuscript and added important comments to the paper. All authors read and approved the final manuscript.

Funding The authors have not declared a specific grant for this research from any funding agency in the public, commercial or not-for-profit sectors.

Competing interests None declared.

Patient consent for publication Not required.

Provenance and peer review Not commissioned; externally peer reviewed.

Data sharing statement № additional data are available.

Open access This is an open access article distributed in accordance with the Creative Commons Attribution Non Commercial (CC BY-NC 4.0) license, which permits others to distribute, remix, adapt, build upon this work non-commercially, and license their derivative works on different terms, provided the original work is properly cited, appropriate credit is given, any changes made indicated, and the use is non-commercial. See: http://creativecommons.org/licenses/by-nc/4.0/.

\section{REFERENCES}

1. Statistisches Bundesamt. Pressemitteilungen - 52 Millionen Operationen und medizinische Prozeduren bei stationären Patienten im Jahr 2013 - Statistisches Bundesamt (Destatis). 2014. Available at https://www.destatis.de/DE/PresseService/Presse/ Pressemitteilungen/2014/10/PD14_368_231.html (Accessed 20 Jun 2017).

2. Turrentine FE, Wang $\mathrm{H}$, Simpson VB, et al. Surgical risk factors, morbidity, and mortality in elderly patients. J Am Coll Surg 2006;203:865-77.

3. Derrington MC, Smith G. A review of studies of anaesthetic risk, morbidity and mortality. Br J Anaesth 1987;59:815-33.

4. Riediger C, Nietlispach F, Rüter F, et al. Kathetergestützte Aortenklappenimplantation: Was müssen Anästhesisten wissen? Anaesthesist 2011;60:1095-108.

5. Motloch LJ, Rottlaender D, Reda S, et al. Local versus general anesthesia for transfemoral aortic valve implantation. Clin Res Cardiol 2012;101:45-53.

6. Oguri A, Yamamoto M, Mouillet G, et al. Clinical outcomes and safety of transfemoral aortic valve implantation under general versus local anesthesia: subanalysis of the French Aortic National CoreValve and Edwards 2 registry. Circ Cardiovasc Interv 2014;7:602-10.

7. Schiff JH, Welker A, Fohr B, et al. Major incidents and complications in otherwise healthy patients undergoing elective procedures: results based on 1.37 million anaesthetic procedures. $\mathrm{Br} J$ Anaesth 2014;113:109-21.

8. Royston D, Cox F. Anaesthesia: the patient's point of view. Lancet 2003;362:1648-58.

9. Matthey P, Finucane BT, Finegan BA. The attitude of the general public towards preoperative assessment and risks associated with general anesthesia. Can J Anaesth 2001;48:333-9.

10. Torossian A. S3-Leitlinie zur Vermeidung von perioperativer Hypothermie 2014. 2014. Available at http://www.awmf.org/leitlinien/ detail/II/001-018.html (Accessed 20 Jun 2017).

11. Rudolph JL, Marcantonio ER. Review articles: postoperative delirium: acute change with long-term implications. Anesth Analg 2011;112:1202-11

12. Rüsch D, Eberhart LH, Wallenborn J, et al. Nausea and vomiting after surgery under general anesthesia: an evidence-based review concerning risk assessment, prevention, and treatment. Dtsch Arztebl Int 2010;107:733-41.

13. Würschinger F, Wittmann S, Goldfuß S, et al. Complications after transcatheter aortic valve implantation using transfemoral and transapical approach in general anaesthesia. PLoS One 2018;13:e0193558.

14. WHO. WHO Global Database on Body Mass Index. http://apps.who. int/bmi/index.jsp?introPage=intro_3.html (Accessed 08 Oct 2016). 
15. Apfel CC, Läärä E, Koivuranta M, et al. A simplified risk score for predicting postoperative nausea and vomiting: conclusions from cross-validations between two centers. Anesthesiology 1999:91:693-700.

16. Monk TG, Bronsert MR, Henderson WG, et al. Association between Intraoperative Hypotension and Hypertension and 30-day Postoperative Mortality in Noncardiac Surgery. Anesthesiology 2015;123:307-19.

17. Pedersen T, Nicholson A, Hovhannisyan K, et al. Pulse oximetry for perioperative monitoring. Cochrane Database Syst Rev 2014:CD002013.

18. Carl M, Alms A, Braun J, et al. S3-Leitlinie zur intensivmedizinischen Versorgung herzchirurgischer Patienten Hämodynamisches Monitoring und Herz-Kreislauf: Kurzfassung. http://www.awmf.org/ leitlinien/detail/I//001-016.html (Accessed 20 Jun 2017).

19. Bundesausschuss $\mathrm{G}$. Richtlinie zu minimalinvasiven Herzklappeninterventionen - MHI-RL - Gemeinsamer Bundesausschuss. https://www.g-ba.de/informationen/richtlinien/84/ (Accessed 20 Jun 2017).

20. Schwilk B, Muche R, Bothner U, et al. Zwischenfälle, Ereignisse und Komplikationen in der perioperativen Phase bei normal- und fehlernährten Patienten - Ergebnisse von 23056 Anästhesien. AINS Anästhesiologie · Intensivmedizin · Notfallmedizin · Schmerztherapie 1995;30:99-107.

21. Scholz AF, Oldroyd C, McCarthy K, et al. Systematic review and meta-analysis of risk factors for postoperative delirium among older patients undergoing gastrointestinal surgery. Br J Surg 2016;103:e21-8

22. Koster S, Oosterveld FG, Hensens AG, et al. Delirium after cardiac surgery and predictive validity of a risk checklist. Ann Thorac Surg 2008;86:1883-7.

23. Maniar HS, Lindman BR, Escallier K, et al. Delirium after surgical and transcatheter aortic valve replacement is associated with increased mortality. J Thorac Cardiovasc Surg 2016;151:815-23.

24. Heymann A, Spies C. Postoperatives Delir und kognitives Defizit. Prävention und Therapie. Anasthesiol Intensivmed Notfallmed Schmerzther 2010;45:112.
25. Apfel CC, Heidrich FM, Jukar-Rao S, et al. Evidence-based analysis of risk factors for postoperative nausea and vomiting. $\mathrm{Br} \mathrm{J}$ Anaesth 2012;109:742-53.

26. Egerod I, Nielsen S, Lisby KH, et al. Immediate post-operative responses to transcatheter aortic valve implantation: An observational study. Eur J Cardiovasc Nurs 2015;14:232-9.

27. Frenzel JC, Kee SS, Ensor JE, et al. Ongoing provision of individual clinician performance data improves practice behavior. Anesth Analg 2010:111:515-9.

28. Hafermann MJ, Namdar R, Seibold GE, et al. Effect of intravenous ondansetron on QT interval prolongation in patients with cardiovascular disease and additional risk factors for torsades: a prospective, observational study. Drug Healthc Patient Saf 2011;3:53-8.

29. Royse CF, Tiernan RJ, Portelli SM, et al. The effect of supplemental oxygen on the incidence of hypoxaemia after premedication in patients undergoing cardiac surgery. Anaesth Intensive Care 1997;25:347-9.

30. Forster A, Gardaz JP, Suter PM, et al. Respiratory depression by midazolam and diazepam. Anesthesiology 1980;53:494-7.

31. Gonzalez Castro LN, Mehta JH, Brayanov JB, et al. Quantification of respiratory depression during pre-operative administration of midazolam using a non-invasive respiratory volume monitor. PLoS One 2017;12:e0172750.

32. Aldecoa C, Bettelli G, Bilotta F, et al. European Society of Anaesthesiology evidence-based and consensus-based guideline on postoperative delirium. Eur J Anaesthesiol 2017;34:192-214.

33. Brecker SJ, Bleiziffer S, Bosmans J, et al. Impact of Anesthesia Type on Outcomes of Transcatheter Aortic Valve Implantation (from the Multicenter ADVANCE Study). Am J Cardiol 2016;117:1332-8.

34. Maas EHA, Pieters BMA, Van de Velde M, et al. General or Local Anesthesia for TAVI? A Systematic Review of the Literature and Meta-Analysis. Curr Pharm Des 2016;22:1868-78.

35. Fröhlich GM, Lansky AJ, Webb J, et al. Local versus general anesthesia for transcatheter aortic valve implantation (TAVR)-systematic review and meta-analysis. BMC Med 2014;12:41. 